\title{
The public health nutrition intervention management bi-cycle: a model for training and practice improvement
}

\author{
Roger Hughes ${ }^{1, *}$ and Barrie Margetts ${ }^{2}$ \\ ${ }^{1}$ School of Public Health, Griffith University, Gold Coast, Queensland 4212, Australia: ${ }^{2}$ Public Health Nutrition, \\ Faculty of Medicine, University of Southampton, Southampton, UK
}

Submitted 12 April 2011: Accepted 25 June 2011: First published online 23 August 2011

\begin{abstract}
Objective: The present paper describes a model for public health nutrition practice designed to facilitate practice improvement and provide a step-wise approach to assist with workforce development.

Design: The bi-cycle model for public health nutrition practice has been developed based on existing cyclical models for intervention management but modified to integrate discrete capacity-building practices.

Setting: Education and practice settings.

Subjects: This model will have applications for educators and practitioners.

Results: Modifications to existing models have been informed by the authors' observations and experiences as practitioners and educators, and reflect a conceptual framework with applications in workforce development and practice improvement. From a workforce development and educational perspective, the model is designed to reflect adult learning principles, exposing students to experiential, problem-solving and practical learning experiences that reflect the realities of work as a public health nutritionist. In doing so, it assists the development of competency beyond knowing to knowing how, showing how and doing. This progression of learning from knowledge to performance is critical to effective competency development for effective practice.

Conclusions: Public health nutrition practice is dynamic and varied, and models need to be adaptable and applicable to practice context to have utility. The paper serves to stimulate debate in the public health nutrition community, to encourage critical feedback about the validity, applicability and utility of this model in different practice contexts.
\end{abstract}

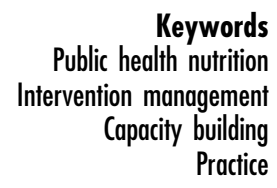

Promoting optimal nutrition is the central focus of public health nutrition (PHN) as a discipline. While some progress has been made internationally in addressing undernutrition, progress has been too slow to achieve the Millennium Development Goals ${ }^{(1,2)}$. Overnutrition, as expressed by rates of overweight and obesity, is rising in most countries ${ }^{(3)}$, with many low- and middle-income countries now suffering a double burden. Many countries have responded by developing policies and action plans that are aimed at addressing these major nutrition problems $^{(4)}$, but they usually ignore issues relating to capacity to implement and the determinants of capacity such as workforce development ${ }^{(5)}$. As a consequence, many nutrition policies and plans are not being effectively implemented $^{(6)}$. Building strategic and operational capacity is recognised as a critical determinant of the effectiveness of local, national and international nutrition systems in delivering optimal nutrition outcomes for populations $^{(2,7)}$. As both forms of capacity are dependent on purposive and multi-strategy investments in workforce

development at all levels in the system, workforce development remains an outstanding and often neglected challenge in our discipline area. Workforce capacity deficits in PHN are a universal problem, even in rich economies with well-developed health systems ${ }^{(5,7-9)}$. The key determinants of workforce capacity that are consistent internationally are summarised in Table 1.

Of the determinants outlined in Table 1 that impact on workforce capacity, workforce preparation and practice improvement are most amenable to change within, and by, the PHN community.

\section{Public health nutrition practice}

PHN practice spans activities that range from academic and analytical work through to working 'in situ' with communities and stakeholders to address nutrition issues. A focus on assessing, strategically changing and evaluating the socio-economic, physical and cultural determinants of 
Table 1 Determinants of public health nutrition $(\mathrm{PHN})$ workforce capacity ${ }^{(5-9,17)}$

\author{
Workforce preparation \\ Practice improvement and \\ learning systems \\ Human resource infrastructure \\ Organisation and policy \\ environment \\ Intelligence access and use
}

\begin{abstract}
Inadequate and/or non-specific training, reliance on clinically trained practitioners
Workforce practices do not reflect required work, limited targeting of interventions to most needy groups, strategy utilisation more aligned to clinical practice, limited environmental change strategy use, limited workforce mentoring, barriers to continuing competency development

Small workforces relative to need, limited specialisation in PHN, high staff turnover, over-reliance on overworked health generalists

Inadequate resource allocation to support action, leadership limited to rhetoric, absence of systematic and strategic workforce development, workforce disorganisation

Suboptimal access to PHN intelligence, under-developed workforce research culture, limited collaboration between practitioners and academics
\end{abstract}

nutritional status affecting health characterises PHN practice $^{(10)}$. As a result, PHN practice involves a complexity that creates significant challenges for the strategic development of the practitioner workforce and its effectiveness. This is exacerbated by changing practice paradigms in the field of nutrition $^{(11)}$, which makes it difficult to apply a comprehensive description of the nature of PHN practice across all practice settings. For the purposes of the present paper, $\mathrm{PHN}$ practice is defined as the work required to effectively develop, implement and evaluate interventions that address identified, population-based nutrition problems. In this context, intervention refers to actions that intentionally focus on changing health outcomes by addressing the determinants of nutritional exposures.

To date the PHN research literature has tended to apply an epidemiological focus on exploring and understanding the determinants and distribution of nutrition issues, and evaluation of interventions. This assumption can be tested by reviewing any issue of this journal. This work has been critically important in understanding what determinants cause nutrition problems, what strategies have merit in terms of producing desired changes in health status and how to measure these changes. Unfortunately, this literature does not provide adequate guidance about how to practise PHN effectively within specific contexts, what work is required and what competencies are required to effectively promote and maintain the nutrition-related health and well-being of populations.

\section{Core functions and competencies}

The lack of consideration of the practice of PHN constrains PHN workforce development, practice effectiveness and overall capacity ${ }^{(12)}$. This has prompted efforts to identify, assess consensus and codify the core functions of the PHN workforce; core functions being those considered absolutely necessary to ensure public health capacity ${ }^{(13)}$. This has been done to help focus workforce development efforts in developed countries such as Australia and the European Union $^{(14-16)}$. This consensus development work has identified intervention management (the design, planning, implementation and evaluation of public health interventions) as a dominant core workforce function (with as much as $50 \%$ of core functions identified reflecting intervention management practices), reinforcing earlier findings in Australia about employer expectations ${ }^{(14)}$ and workforce practices ${ }^{(17)}$. Capacity-building functions are similarly rated as core functions, reinforcing the long-held view of capacity building as an important strategic approach in developing country PHN practice ${ }^{(18,19)}$.

If an understanding of the core functions (the work) of the PHN workforce is a prerequisite for strategic workforce development, there is a powerful logic in aligning core functions with the competencies required to perform these functions ${ }^{(20)}$; competencies here referring to the knowledge, skills and 'ways of thinking' required to effectively perform a work function ${ }^{(21)}$. In practice, the competency mix required to effectively manage interventions and build capacity has been shown to be quite broad, drawing on a mix of analytical, management, strategic planning, leadership and organisational competencies ${ }^{(22,23)}$. Unfortunately, there is limited scholarship about the most effective and efficient methods to develop these competencies in our disciplinary literature. To help address this gap, the present paper describes a new model for PHN intervention management practice designed to facilitate practice improvement and provide a step-wise approach to assist with PHN workforce preparation.

\section{Step-wise processes to guide practice}

Step-wise processes for practice and learning have been widely applied conceptual devices used to help bring order to this complexity in health practice and education. PHN practice borrows heavily from the related disciplines of health promotion, public health and dietetics, and has adopted many of the practice cycles that have evolved in these disciplines ${ }^{(24)}$, which are all loosely based on action research processes that include cycles of planning, acting, observing and reflecting ${ }^{(25)}$. Cyclical and systematic processes for intervention management and practice have been used for many years to inform strategic decision making and to enhance the quality and effectiveness of intervention management ${ }^{(26,27)}$. These have varied in terms of the degree of segmentation in the step-wise cycle. The Triple-A cycle $\mathrm{e}^{(28)}$ that includes three main steps of Analysis, Action and Assessment was developed to assist with interventions dealing with malnutrition. 
Intervention mapping was proposed in the late 1990s as a sequential process of integrating theory, empirical findings from the literature and information collected from the population to inform strategic decision making about how best to address health promotion challenges ${ }^{(29)}$. Borrowing from these earlier models, the PHN cycle ${ }^{(24)}$ has been proposed as a seven-step practice cycle to describe the nature of PHN practice. This model replicates the basic cycle of needs assessment, planning, implementation and evaluation used in earlier health promotion planning models. Both of these earlier PHN practice cycles have more recently been adapted in an attempt to more explicitly integrate capacity-building principles and practice as part of the process of developing sustainable interventions ${ }^{(30)}$.

As models for informing PHN practice and workforce development, we believe these earlier models have limitations in the context of workforce development and practice improvement in that they do not adequately deconstruct practice in a way that can inform responses to the "where do I start?', 'how?' and 'with who?' type questions that are important in teaching students PHN practice competencies. They similarly do not reflect a notion of progress in practice (moving forward rather than going around-andaround), and they do not adequately integrate capacitybuilding strategies with project planning in a step-by-step sequence.

\section{A bi-cyclic framework for public health nutrition practice}

We propose a bi-cyclic model for PHN practice ('the bi-cycle'; Fig. 1) over three distinct stages, to inform workforce development and practice in the core practice area of intervention management. This model recognises the progressive and cumulative nature of PHN practice (i.e. moving forward) and integrates capacity building into the planning-implementation-evaluation sequence. This practice framework emphasises the process, tools and rationale for practice approaches in PHN. To encourage discipline in PHN practice, it is intentionally pedantic in the way that it has deconstructed earlier models into what may seem to be overly numerous discrete steps, which are summarised in Table 1.

\section{Different phases in practice}

The intelligence phase, represented by the first loop in the bi-cycle, forces practitioners to engage with their communities and key stakeholders and understand the problem and contextual factors before acting; intelligence in this context referring to information from various sources and methods that help inform decision making about intervention design. Understanding before acting means careful and varied analysis of the community, the community's capacity for action, the problems faced and what determinants have a causal relationship with the problem - the logic being that until 'upstream' determinants that need to be changed are identified, it is difficult to develop strategies that will lead to a change in 'downstream' health outcomes. The action phase of PHN practice, represented by the connection between the intelligence and evaluation loops in the bi-cycle, focuses on planning and managing intervention implementation. The evaluation phase in the PHN practice bi-cycle focuses on the different levels and types of evaluation, and emphasises the importance of sharing practice leanings via dissemination and scholarship.

\section{Feedback between cycles}

The backward arrow linking the action phase with evaluation and intelligence phases (the bi-cycle's chain) represents the dynamic nature of intervention management that regularly requires practitioners to go back to the intelligence, to fine-tune strategies and adapt to changing contexts in practice. It also illustrates that evaluation builds on the intelligence required to inform practice.

\section{Improving practice}

PHN practice, to be effective, needs to be dynamic, responsive and contextual to the setting, situation and available resources. Without an intentional and strategic emphasis on the capacity-building approach to practice, PHN practice and the resultant interventions are likely to produce disappointing returns on investment in terms of outcomes relative to resources used. The bi-cyclic model for practice provides a systematic process for intervention management that has applications irrespective of the issues being addressed, the practice context, the strategy mix and the level of intervention. It integrates capacity-building steps (steps 1, 3, 5, 6, 7, 15, 17) into the sequential practice cycle, making it an explicit approach to practice consistent with previous arguments about the need to bring capacitybuilding strategies to the forefront of PHN practice ${ }^{(30,31)}$. Our proposition then is that this model, if applied in practice, will enhance practice effectiveness compared with earlier less integrated approaches and serve a useful practice improvement function.

\section{Workforce preparation}

We believe that the model has its greatest utility in the development of PHN practice competencies during workforce preparation, both in the pre-employment and post-employment (continuing education) stages of workforce development. We have previously used the bi-cycle model as a framework for curriculum development and instructional design in the courses and texts ${ }^{(32)}$ we use to teach in our respective universities, as a framework for a PHN workforce mentoring intervention ${ }^{(33)}$ and a suite of online learning modules has been developed as part of the JobNut Project funded by the European Union (http://www.medicine.tcd.ie/nutrition-dietetics/jobnut/). 

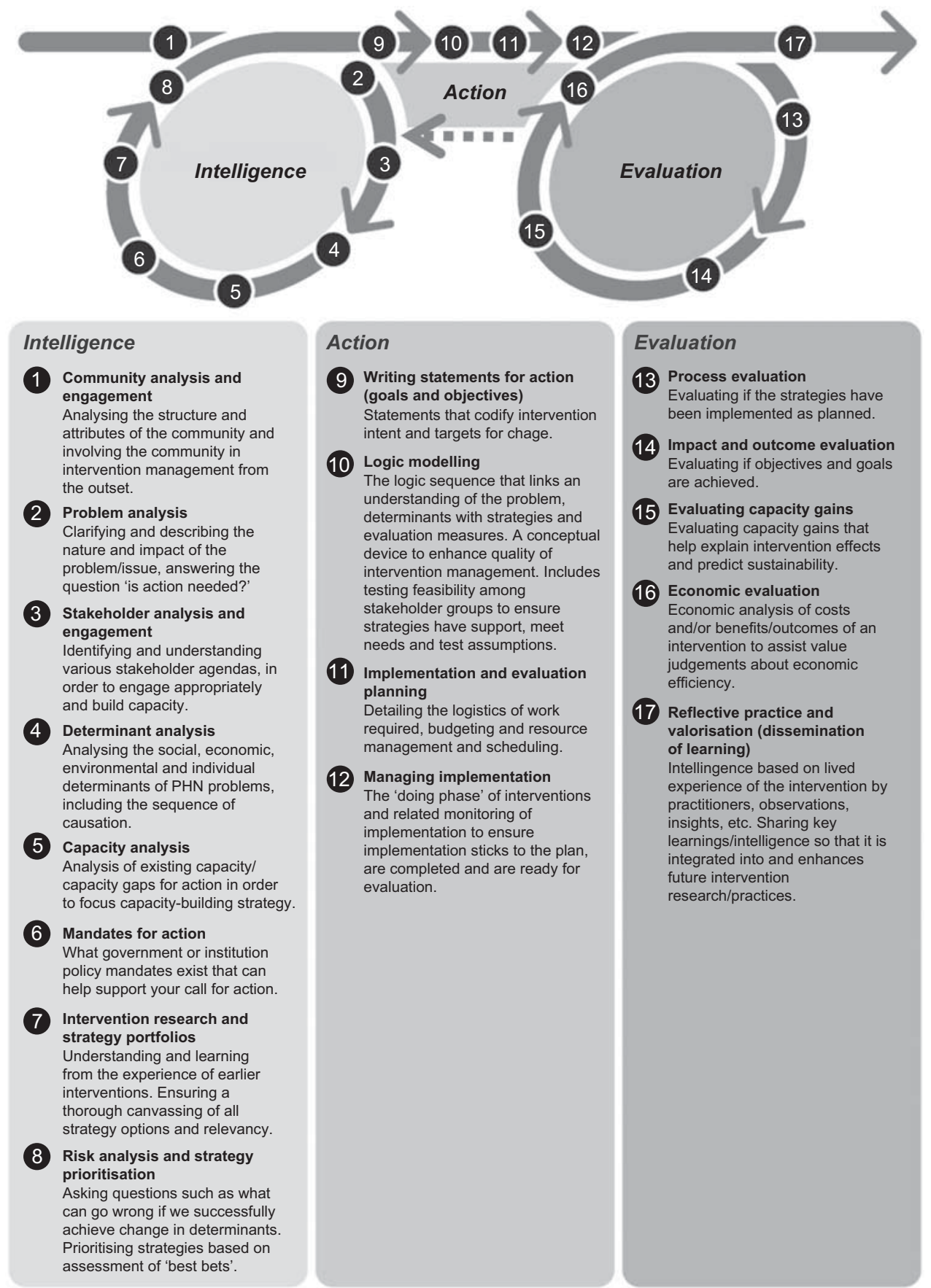

Fig. 1 The bi-cycle framework for public health nutrition $(\mathrm{PHN})$ practice $^{(32)}$

Each step provides an opportunity to engage students in learning and skill development regarding the rationale in practice, techniques and tools to assist with $\mathrm{PHN}$ practice in a sequential manner. We have used the model to guide students develop comprehensive PHN intervention plans as a basis for assessment and later practicebased implementation during professional internships. In the process, we believe we are preparing students to be employable, effective in practice and to be catalysts for change.
Table 2 aligns each step in the practice cycle with a summary of the competency elements derived from recently published $\mathrm{PHN}$ academic standards ${ }^{(21)}$ required at each step and some of the learning and teaching strategies that can be used to build these competencies.

\section{Learning and teaching rationale}

From an androgogical (adult learning and teaching) perspective, the bi-cycle model provides a conceptual framework to structure experiential learning that reflects the key 
Table 2 The bi-cycle framework for public health nutrition practice: aligning practice, competencies and learning and teaching strategies

3 Stakeholder analysis and engagement

4 Determinant analysis

$5 \quad$ Capacity analysis

6 Mandates for action

$7 \quad$ Intervention research and strategy portfolios

8 Risk analysis and strategy prioritisation

Competency elements ${ }^{(21) \star}$

EK NS AN PHSK FNSK NE MGT LDR PROF COM NAMS CB

Sourcing, analysing and interpreting mixed-source data in a local/real community using research and

community engagement strategies

Problem description and profiling using

available epidemiological data, burden of
illness data, community needs data, etc.

Requires learners to make explicit the focus of action

Using stakeholder analysis tools such as stakeholder analysis grids ${ }^{(36)}$ that consider different categories of

stakeholders in the problem context,

considering constructs such as power and interest

Determinant analysis diagrams that make explicit the factors/determinants that contribute to the problem identified including the interactions and sequence of each determinant's effects

Analysis and description of local capacity to address the problem identified, using techniques such as force field analysis ${ }^{(36)}$ or checklists that explicitly outline elements of capacity to act

dentifying and drafting statements that position required action in the context of existing government and institutional mandates for action

Critical and systematic assessment of previous interventions to identify intervention context, strategy application, evidence of effectiveness and key learning for practice. Learners can be tasked to draft justifications for a portfolio of strategies to address the defined problem based on available intervention research, with particular attention to the contextual issues presented by the localised problem Learners can be tasked to consider unintended effects of strategy

implementation as a basis for managing associated risks and to prioritise strategies with a justification for this prioritisation, considering key prioritisation issues such as size and seriousness of the problem, effectiveness of strategies and propriety, economics, acceptability, resource and legal issues ${ }^{(37)}$ 
Competency elements ${ }^{(21) *}$

\begin{tabular}{|c|c|c|c|c|c|c|c|c|c|c|c|c|c|c|c|c|}
\hline$\overline{\text { Action }}$ & \multirow{2}{*}{$\begin{array}{c}\text { Step } \\
9\end{array}$} & \multicolumn{2}{|c|}{ Learning and teaching exercises: examples } & \multirow{2}{*}{$\frac{\text { EK }}{+}$} & \multirow[t]{2}{*}{ NS } & \multirow{2}{*}{$\frac{\text { AN }}{+}$} & \multirow[t]{2}{*}{ PHSK } & \multirow[t]{2}{*}{ FNSK } & \multirow[t]{2}{*}{$\mathrm{NE}$} & \multirow{2}{*}{$\begin{array}{c}\text { MGT } \\
+\end{array}$} & \multirow[t]{2}{*}{ LDR } & \multirow[t]{2}{*}{ PROF } & \multirow{2}{*}{$\frac{\text { COM }}{+}$} & \multirow{2}{*}{$\frac{\text { NAMS }}{+}$} & \multirow[t]{2}{*}{$\mathrm{CB}$} & \multirow{2}{*}{$\begin{array}{c}\mathrm{IM} \\
+\end{array}$} \\
\hline Action & & $\begin{array}{l}\text { Writing statements } \\
\text { for action }\end{array}$ & $\begin{array}{l}\text { Learners can be tasked to write goals and } \\
\text { objectives that clearly relate to the } \\
\text { determinants and problem defined in } \\
\text { earlier steps, the emphasis being on } \\
\text { identifying modifiable determinants, the } \\
\text { anticipated change in the problem } \\
\text { associated with change in determinants, } \\
\text { so that action statements drafted are } \\
\text { specific, measurable, achievable, realistic } \\
\text { and time-specific (SMART) }\end{array}$ & & & & & & & & & & & & & \\
\hline & 10 & Logic modelling & $\begin{array}{l}\text { Logic modelling involves diagrammatically } \\
\text { representing the logic and assumptions } \\
\text { underpinning an intervention's strategy } \\
\text { mix, including the anticipated cause-effect } \\
\text { of strategy implementation through to } \\
\text { evaluation of changes in determinants and } \\
\text { related outcomes. Tasking learners to } \\
\text { make explicit this logic forces learners to } \\
\text { critically reflect on assumed cause-effect } \\
\text { of strategies }\end{array}$ & + & + & + & + & + & & & & & + & & & + \\
\hline & 11 & $\begin{array}{l}\text { Implementation and } \\
\text { evaluation planning }\end{array}$ & $\begin{array}{l}\text { Learners can be tasked to consider the } \\
\text { logistics of strategy implementation by } \\
\text { deconstructing strategies into work } \\
\text { packages/tasks, considering the } \\
\text { sequence of work required and the } \\
\text { associated human and other resources } \\
\text { required (budgeting). These exercises } \\
\text { provide assessable products based on } \\
\text { experiential learning (learning by doing) }\end{array}$ & + & + & + & + & + & & + & & & + & & & + \\
\hline & 12 & $\begin{array}{l}\text { Managing } \\
\text { implementation }\end{array}$ & $\begin{array}{l}\text { Evaluability assessment involves assessing } \\
\text { whether or not an intervention is ready for } \\
\text { evaluation }{ }^{(38)} \text {. Learners can conduct an } \\
\text { evaluability assessment on an intervention } \\
\text { scenario using a step-wise assessment } \\
\text { worksheet. This exercise focuses } \\
\text { learners' attention to questions of strategy } \\
\text { exposure, extent of implementation and } \\
\text { available evaluation data }\end{array}$ & + & & & & & & + & + & + & + & & & \\
\hline Evaluation & 13 & Process evaluation & $\begin{array}{l}\text { The key learning task associated with issues } \\
\text { of all forms of evaluation is in the design of } \\
\text { evaluation methods to effectively measure } \\
\text { achievement against goals and objectives, } \\
\text { to assess intervention implementation, } \\
\text { capacity gains and to make judgement } \\
\text { about costs } v \text {. outcomes. Learners can be } \\
\text { tasked to develop and justify evaluation } \\
\text { plans, reflecting expectations in practice }\end{array}$ & + & + & + & + & + & & & & & + & + & + & + \\
\hline
\end{tabular}


motivations for adult learning. These motivations include needing to know the reason for learning something, experience as a basis for learning, involvement in the planning and evaluation of their instruction, learning of immediate relevance to their work lives and learning that is problem centred ${ }^{(34)}$. This approach goes beyond didactic teaching for knowing to teaching so that learners can 'know how', 'show how' and 'do, ${ }^{(35)}$. This model has an intentional focus on developing the meta-cognitive aspects of practitioner competency, including ways of thinking about problems and possible solutions, making decisions and reflecting on practice in order to continue learning and improving practice. It therefore can be an important part of the process of professionalisation required in the preparation and continuing education of PHN professionals. As Table 2 illustrates, the breadth of competency development opportunities that working through the bi-cycle step-wise process presents suggests it has potential as the basis for a comprehensive approach to PHN competency development as a curriculum component.

\section{Conclusions}

The bi-cycle model for PHN practice is proposed as a new framework for workforce development and practice improvement that builds on earlier models. As a conceptual model designed to assist a disciplined and sequential process for practice and learning, that integrates capacity building with intervention management, we have found it useful as a scaffold for learning interventions, competency development and critical reflection on PHN practice. The assumption that this model, if applied in practice, will more effectively enhance public health outcomes than other less systematic and intentional approaches to practice is yet to be substantially and objectively evaluated. This is currently a focus of ongoing work. We acknowledge that PHN practice is dynamic and varied, and that models need to be adaptable and applicable to practice context, to have utility. The present paper serves to stimulate debate in the PHN community, to encourage critical feedback about the validity, applicability and utility of this model in different practice contexts.

\section{Acknowledgements}

This research received no specific grant from any funding agency in the public, commercial or not-for-profit sectors. There are no conflicts of interest. R.H. took the principal role in conceptualising the model and drafting and finalising the paper. B.M. contributed to model conceptualisation, paper drafting and editing. The development of the bi-cycle model has been assisted by feedback from many of our students over the past decade and input from our colleagues Christina Black, Jenny Davies and Nick Kennedy. The constructive suggestions from the reviewers have contributed to the fine-tuning of this paper, and are acknowledged. 


\section{References}

1. Bryce J, Coitinho D, Darnton-Hill I et al. (2008) Maternal and child undernutrition: effective action at national level. Lancet 371, 510-526.

2. Morris S, Coghill B \& Uauy R (2008) Effective international action against undernutrition: why has it proven so difficult and what can be done to accelerate progress? Lancet $\mathbf{3 7 1}$, 608-620.

3. World Health Organization (2011) Overweight and Obesity: Fact Sheet 311. Geneva: WHO; available at http:// www.who.int/mediacentre/factsheets/fs311/en/index.html

4. Lachat C, Van Camp J, De Henauws S et al. (2005) A concise overview of national nutrition action plans in the European Union Member States. Public Health Nutr 8, 266-274.

5. Margetts B (2009) Promoting the Public Health Nutrition Workforce in Europe. Final Report of the Jobnut Project. Southampton: University of Southampton.

6. Nishida C, Shrimpton R \& Darnton-Hill I (2009) Landscape analysis on countries' readiness to accelerate action in nutrition. SCN News 37, 4-9.

7. Hughes R (2006) A socioecological analysis of the determinants of national public health nutrition work force capacity: Australia as a case study. Fam Community Health 29, 55-67.

8. Fox A, Chenhall C, Traynor M et al. (2008) Public health nutrition practice in Canada: a situational assessment. Public Health Nutr 11, 773-781.

9. Haughton B \& George A (2008) The Public Health Nutrition workforce and its future challenges: the US experience. Public Health Nutr 11, 782-791.

10. Hughes R (2003) Definitions for public health nutrition: a developing consensus. Public Health Nutr 6, 615-620.

11. Jonsson $\mathrm{U}$ (2010) The rise and fall of paradigms in world food and nutrition policy (Commentary). World Nutr 1, 128-158.

12. Hughes R (2003) Public health nutrition workforce composition, core functions, competencies and capacity: perspectives of advanced level practitioners in Australia. Public Health Nutr 6, 607-613.

13. National Public Health Partnership (2000) National Delphi Study on Public Health Functions in Australia. Victoria: NPHP.

14. Hughes R (2004) Employers expectations of core functions and competencies for the public health nutrition workforce. Nutr Diet 61, 105-111.

15. Jonsdottir S (2008) Measurement and development of European consensus on core competencies and curricula required for effective public health nutrition practice. MSc Thesis, University of Iceland.

16. Hughes R (2007) Practices overview. In Public Health Nutrition: From Principles to Practice, pp. 265-272 [M Lawrence and A Worsley, editors]. Crows Nest, NSW: Allen \& Unwin.

17. Hughes R (2004) Work practices of the community and public health nutrition workforce in Australia. Nutr Diet 61, 38-45.

18. Elmadfa I (2006) Mysore declaration: capacity strengthening in nutrition. Ann Nutr Metab 50, 403-406.

19. Shrimpton R (2002) Nutrition in communities. Nutrition: a foundation for development. http://www.unscn.org/files/ Publications/Briefs_on_Nutrition/Brief11_EN.pdf (accessed November 2010).
20. Hughes R (2003) A conceptual framework for intelligencebased public health nutrition workforce development. Public Health Nutr 6, 599-605.

21. Hughes R, Shrimpton R, Recine E et al. (2011) A competency framework for global public health nutrition workforce development. Draft report. Gold Coast, QLD: Griffith University.

22. Jonsdottir S, Hughes R, Thorsdottir I et al. (2011) Consensus on the competencies required for public health nutrition workforce development in Europe - the JobNut project. Public Health Nutr 14, 1439-1449.

23. Hughes R (2003) Competencies for effective public health nutrition practice: a developing consensus. Public Health Nutr 7, 683-693.

24. Margetts B (2004) An overview of public health nutrition. In Public Health Nutrition, pp. 1-25 [B Margetts, M Gibney, J Kearney et al., editors]. Oxford: Blackwell Publishing.

25. Lewin K (1947) Frontiers in group dynamics. Hum Relat 1, 5-41.

26. Godin G, Gagnon H, Alary M et al. (2007) The degree of planning: an indicator of the potential success of health education programs. Promot Educ XIV, 138-142.

27. Ader M, Berensson K, Carlsson P et al. (2001) Quality indicators for health promotion programmes. Health Promot Int 16, 187-195.

28. Jonsson U (1988) A conceptual approach to understanding and explanation of hunger and malnutrition in society. In Hunger and Society. Cornell International Monograph Series no. 17. Ithaca, NY: Cornell University Program in International Nutrition.

29. Bartholomew K, Parcel G, Kok G et al. (2001) Intervention Mapping: Designing Theory- and Evidence-based Health Promotion Programs. New York: McGraw-Hill Companies.

30. Baillie E, Bjarnholt C, Gruber M et al. (2009) A capacitybuilding conceptual framework for public health nutrition practice. Public Health Nutr 12, 1031-1038.

31. Labonte R, Woodward C, Chad K et al. (2002) Community capacity building: a parallel track for health promotion programs. Can J Public Health 93, 181-182.

32. Hughes R \& Margetts B (2011) Practical Public Health Nutrition. Oxford: Wiley Blackwell.

33. Palermo C, Hughes R \& McCall L (2010) Developing the nutrition and dietetics workforce after graduation: a mixedmethod evaluation of a workforce development intervention. J Hum Nutr Diet 23, 244-253.

34. Knowles M, Holton E \& Swanson R (2005) The Adult Learner: The Definitive Classic in Adult Education and Human Resource Development, 6th ed. Boston, MA: Elsevier.

35. Miller G (1990) The assessment of clinical skills/competence/performance. Acad Med 65, 9 Suppl., S63-S67.

36. Deutsche Gesellschaft fur Technische Zusammenarbeit (2005) Capacity Building Needs Assessment (CBNA) in the Regions (version 2.0) Module B. Methods and Instruments for the Capacity Building Cycle. Jakarta: GTZ.

37. Pickett G \& Hanlon J (editors) (1990) Public Heath: Administration and Practice. St Louis, MO: Times Mirror/ Mosby College Publishing.

38. Hawe P, Degeling D \& Hall J (editors) (1990) Evaluating Health Promotion: A Health Worker's Guide. Sydney: MacLennan and Petty. 